\title{
EPR 机组热试注锌钝化的应用探讨
}

\section{Discussion on Application of Hot Test Injection Zinc Passivation in EPR Units \\ 张英良}

Yingliang Zhang

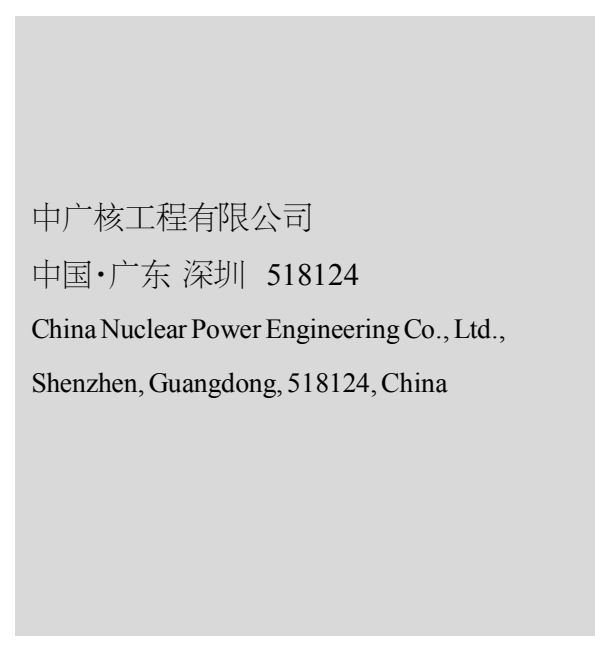

\section{1 引言}

注锌技术源于沸水堆 (BWR) 机组, 20 世纪 80 年代后期 开始在沸水堆中应用, 用于减缓一回路管道设备的应力腐蚀、 降低辐射剂量率、缓解金属晶间腐蚀。早在 1989-1992 年,美 国西屋公司便根据沸水堆应用效果, 开始针对压水堆 (PWR) 进行一回路注锌研究。在 2009 年, 日本 Tomari 核电站 3 号机 组完成热态功能试验(热试)中的注锌钝化, 为世界上首次。在 中国,引入的三代核电 AP1000 机组中, 在设计时即考虑了注 锌技术的应用, 并在调试介段的热试中便开始向一回路中注 锌[1]。在 EPR 三代核电机组中, 同样考虑了注锌技术的应用, 并在热试期间进行注锌钝化。文章主要介绍 EPR 机组热试期 间注锌钝化的目的、实施过程及监测, 为后续机组实施热试注 锌钝化提供参考。

\section{2 目的}

根据国际上的电厂应用注锌技术的反馈, 反应堆一回路 注锌可使锌离子混入金属内表面的氧化膜中, 带来如下的益 处:减缓一回路金属的持续腐蚀; 降低一回路应力腐蚀破坏发 生的几率; 减少核电站的辐射剂量率; 降低腐蚀产物堆积导致 的堆内功率偏移及由此引起的局部腐蚀的风险。

在充满高温高压水的一回路中, 金属表面所形成的氧化 产物常分为两层, 里层为较致密的保护性氧化膜, 结构通常为 $\mathrm{AB}_{2} \mathrm{O}_{4}$ 形的结构。外层则为较疏松的氧化物。当 $\mathrm{Zn}$ 离子被加
入到一回路中后, $\mathrm{Zn}$ 离子可与一回路金属材料表面的 $\mathrm{NiCr}_{2} \mathrm{O}_{4} 、 \mathrm{FeCr}_{2} \mathrm{O}_{4} 、 \mathrm{CoCr}_{2} \mathrm{O}_{4}$ 等尖晶石氧化膜中的 $\mathrm{Fe}^{2+} 、 \mathrm{Co}^{2+}$ 或 $\mathrm{Ni}^{2+}$ 等阳离子交换, 或嵌入氧化膜中空余的阳离子位置, 形成结构 更致密的 $\mathrm{ZnCr}_{2} \mathrm{O}_{4}$ 尖晶石。新形成的氧化膜变得更薄更致密, 从而有效降低氧化物的生成速率, 减缓腐蚀行为的发生。Zn 离子优先置换进入一回路金属内表面的氧化膜中, 减少了 Co-58 与 $\mathrm{Co}-60$ 的结合, 降低了一回路的辐射剂量率。

在热试钝化期间即进行注锌工作, 可以增加正式运行前 主系统内表面与锌的接触时间, 并且热试期间未装载核燃料, 置换出的其他金属离子不会增加额外的放射性产物。因此效 果将优于已运行多年后应用注锌的机组。热试时注锌钝化, 对 辐射剂量率的控制效果优于在已运行多年机组中注锌, 后述 运行多年后的机组中, 由于 Co 离子等处于氧化膜深处,会缓 慢的被 Zn 离子置换, 辐射剂量率会逐渐降低, 效果缓慢。

\section{3 注锌过程与监测}

\section{1 选择锌离子溶剂及目标浓度}

根据国际上电厂应用注锌技术的反馈, 在功率运行阶段 进行注锌时, 可采用天然醋酸锌或贫化醋酸锌, 天然醋酸锌含 有 $48.6 \%$ 的 ${ }^{64} \mathrm{Zn}$ 加入到一回路后, ${ }^{6} \mathrm{Zn}$ 经中子活化产生 ${ }^{65} \mathrm{Zn}$, ${ }^{65} \mathrm{Zn}$ 衰变会产生 $1.1 \mathrm{MeV}$ 的 $\gamma$ 射线, 半衰期为 $243.8 \mathrm{~d}$ 。贫化醋 酸锌中 ${ }^{67} \mathrm{Zn}$ 的含量小于 $1 \%$, 可使放射剂量大为降低, 但是制 备复杂价格较昂贵。为使后续功率运行时减小辐射的效果最 优,推荐使用贫化锌。 
经验交流 Experience Exchange

在已运行的机组中应用注锌技术时, 一般冷却剂回路中 加入锌的浓度为 5 40ppb, 采用较低浓度注锌 (5 10ppb), 主 要目的是为了降低辐射剂量率, 较高浓度注锌 (15 40ppb) 则 主要是为了减缓 PWSCC。在中国 AP1000 机组热试注锌时, 锌浓度控制在 $10 \pm 5 \mathrm{ppb}$ 。在 EPR 机组热试注锌钝化期间, 可 设定锌浓度期望值为 40 60ppb, 限值为 15 70ppb, 因热试期 间未装燃料, 且钝化时间规定仅有 $300 \mathrm{~h}$, 因此便采用了较高 的浓度以便更快的置换 $\mathrm{Co}-60$ 和 $\mathrm{Co}-58$ 等离子。

\section{2 注锌系统与装置}

EPR 机组热试期间执行注锌钝化时,在开始计时前利用 $\operatorname{RCV}$ (化学和容积控制系统)进行加锌, 利用上充百向反应堆 冷却剂系统提供醋酸锌。

\section{3 加锌后的监测与跟踪}

注锌前应制定化学控制手册, 明确注锌的浓度控制范围、 注入速率、开始及停止添加的标准、取样频率、锌测量方法及 纠正行动等。据此编写相应的机组加锌化学技术规范, 如表 1 所示。

注锌刚开始时, 由于锌与一回路中的金属离子置换, 导致 刚开始时浓度较低, 出现测量不到的情况,一段时间之后, Zn 浓度才会逐渐增加, 达到目标浓度, 需密切监视该时间段内
$\mathrm{Zn}$ 离子浓度, 合理判断注锌浓度与速度。

表 1 热试与加锌相关的化学控制

\begin{tabular}{|c|c|c|c|c|c|c|}
\hline 参数 & 单位 & \begin{tabular}{|c|} 
期望 \\
值
\end{tabular} & 限值 & 取样频率 & 限期 & 纠正行动 \\
\hline \multirow{5}{*}{$\begin{array}{l}\mathrm{Zn} \\
\text { 浓度 }\end{array}$} & \multirow{5}{*}{$\mu \mathrm{g} / \mathrm{kg}$} & & & \multirow{5}{*}{$\begin{array}{l}\text { (1)钝化开始前确保 } \\
\text { Zn 浓度合格 } \\
\text { (2)正常情况下, } 1 \text { 次/ } \\
\text { 天 } \\
\text { (3)如果浓度超出期望 } \\
\text { 值, } 2 \text { 次/天 } \\
\text { (4)如果浓度超出限 } \\
\text { 值, } 3 \text { 次/天 }\end{array}$} & 2 天 & \multirow{5}{*}{$\begin{array}{l}\text { 调整注锌浓度或 } \\
\text { 注人速度, 在限 } \\
\text { 期内恢复 Zn 浓 } \\
\text { 度至正常值; 增 } \\
\text { 加取样频率, 如 } \\
\text { 有必要, 可延长 } \\
\text { 钝化时间 }\end{array}$} \\
\hline & & $\geqslant 40$ & $>15$ & & & \\
\hline & & & & & - & \\
\hline & & \multirow[b]{2}{*}{$\leqslant 60$} & \multirow[b]{2}{*}{$<70$} & & 2 天 & \\
\hline & & & & & 1 天 & \\
\hline
\end{tabular}

\section{4 结语}

综上所述, 注锌技术作为一种对减缓主系统材料腐蚀、降 低辐射剂量率、减少燃料表面积垢都有显著效果的技术, 也可 用于 EPR 机组中。特别是作为新建机组, 从热试时注锌, 所形 成效果将优于已运行多年后再应用注锌的情况, 具体实际效 果还需在运行期间对比未注锌钝化的机组。文章所述方法也 可为华龙一号等机组执行加锌钝化提供参考, 制订加锌钝化 技术规范以降低机组辐射水平。

\section{参考文献}

[1]姜苏青.注锌对压水堆核电站一回路结构材料腐蚀行为影响 的研究 $[\mathrm{D}]$.上海: 上海交通大学机械与动力工程学院,2011.

\section{（上接第 27 页）}

国际能源供需格局以及国际能源发展出现了新趋势, 必须从 保障国家能源安全的全局高度，坚决执行“四个革命、一个合 作”能源安全新战略, 与周边国家开展电力合作, 优化中国能 源消费结构, 多元化中国能源输人,保障国家能源安全供应。

\section{4 新服务}

能源电力需求将长期保持增长。目前, 中国人均用电量不 到发达国家一半,未来电力发展空间仍然较大。中央高层会议 多次聚焦新型基础设施建设, 以硬核科技补短板、促增长, 包 括 $5 \mathrm{G}$ 基建及应用、光伏电网及特高压、工业互联网、城际高 速铁路和城际轨道交通、新能源车及充电桩、人工智能、云计 算大数据中心等 7 大领域,并冠以“新基建”概念。电力投资尤 其需要围绕 “新基建”核心议题,转向技术、营销及商业模式创 新。清洁绿色发展将进一步加快。近年来, 全球气候和环境问 题日益严峻, 各国政府都深刻认识到基于传统化石能源的发 展模式不可持续,转而大力发展可再生能源。

\section{5 新技术}

“互联网+能源” 是未来能源发展的必然方向。电力企业 处于能源革命的中心环节, 要充分认识电力系统的枢纽地位。
信息技术与电力行业深度结合。能源技术和信息技术加快融 合, 塑造着第四次工业革命的五大支柱, 促进能源互联网加快 发展,形成了鲜明的时代特征。随着信息技术的进步,尤其是 分布式技术、物联网、云计算、大数据、人工智能、 $5 \mathrm{G}$ 的应用, 大量信息的采集、处理、分析及管理,推动能源生产技术创新、 传输技术、消费技术、管理技术的创新和发展, 适应新时代电 力发展与服务的新趋势。

\section{3 启示与建议}

“十四五” 战略规划是一项抓当前、管长远的系统工程。面 对这些新经济、新安全、新技术等发展趋势特点, 电力企业必 须深入分析总结企业现状和发展定位, 做好 “十四五”规划编 制工作, 体现宏观性、战略性、前瞻性以及指导性等综合要求, 准确把握发展机遇, 充分发挥竞争优势, 以规划为导向, 用规 划明确发展定位、方向和目标措施, 确保企业正确的发展方 向, 提升企业的发展水平, 凝聚企业人心、统一企业行动, 促进 发展质量效益提升。

\section{参考文献}

[1]卡普兰,诺顿.战略地图化无形资产为有形成果 $[\mathrm{M}]$.刘俊勇,孙 薇, 译.广州:广东经济出版社,2005. 